\title{
Desenvolvimento de Ferramenta Online Para o Direito à Saúde: A Rede Ibero-Americana de Direito Sanitário
}

\author{
Maria Célia Delduque $^{a}$ Sandra Mara C. Alves ${ }^{a}$ Marcelo S. Jesus ${ }^{b}$ \\ ${ }^{a}$ Rede Ibero-Americana de Direito Sanitário, Fundação Oswaldo Cruz-Fiocruz, Rio de Janeiro, Brazil; \\ ${ }^{b}$ Fundação Oswaldo Cruz-Fiocruz, Rio de Janeiro, Brazil
}

\section{Palavras Chave}

Network · Cooperation network · Right to health .

Iberoamerican region

\section{Resumo}

$\mathrm{O}$ artigo versa a instalação e funcionamento da rede sociotécnica denominada Rede Ibero-Americana de Direito Sanitário no ciberespaço que constitui uma instância académica destinada a estudos e pesquisas na área do direito à saúde, composta por universidades e institutos de ensino e pesquisa dos países das Américas e da Região lbérica. $O$ estudo apresenta as bases teórica e metodológica em que se baseia a estrutura da rede de cooperação técnica e científica utilizando o método de estudo de caso. $O$ estudo aponta para uma profícua produção intelectual no tema do direito à saúde, especialmente concentrada em sub-redes no âmbito de uma network de maior abrangência. Conclui que com as distâncias físicas em escala continental, a utilização desta rede alargada como opção de trabalho em grupo tem sido reconhecida em termos da sua eficiência e eficácia.

(c) 2017 The Author(s). Published by S. Karger AG, Basel on behalf of Escola Nacional de Saúde Pública

\section{Development of an Online Tool for Health Law: The Iberoamerican Health Law Network}

\author{
Keywords \\ Network - Cooperation network · Right to health . \\ Iberoamerican region
}

\section{Abstract}

The article is about the so-called socio-technical network Iberoamerican Network of Health Law in cyberspace which is an academic network for studies and research on the right to health made up by universities and scientific institutes of countries from the Americas and the Iberian region. The article aims to present the theoretical and methodological foundations underpinning the structure of technical and scientific cooperation networks using the case study method. It shows an intellectual production, especially concentrated in sub-networks, within a wider coverage network. It concludes that the physical distances on a continental scale make the use of a wide network an option for group work that is being recognized by its efficiency and effectiveness.

๑ 2017 The Author(s). Published by S. Karger AG, Basel on behalf of Escola Nacional de Saúde Pública

\section{KARGER}

E-Mail karger@karger.com www.karger.com/pjp (c) 2017 The Author(s). Published by S. Karger AG, Basel on behalf of Escola Nacional de Saúde Pública Karger

Open access

This article is licensed under the Creative Commons AttributionNonCommercial-NoDerivatives 4.0 International License (CC BYNC-ND) (http://www.karger.com/Services/OpenAccessLicense) Usage and distribution for commercial purposes as well as any distribution of modified material requires written permission.
Prof. Maria Célia Delduque, $\mathrm{PhD}$

Fundação Oswaldo Cruz-Fiocruz, Campus Darcy Ribeiro Gleba A SC-4 Avenida L-3 Norte

Rio de Janeiro, Brasília (Brasil)

E-Mail maria.delduque@ fiocruz.br 


\section{Introdução}

A figura de uma rede é a imagem mais usada para designar ou qualificar sistemas, estruturas ou desenhos organizacionais. É uma ação humana, um padrão organizativo em que se envolvem vários atores com o objetivo de promover a transformação da realidade, embutidos em seus princípios e procedimentos. Um dos pioneiros nos estudos interdisciplinares que utilizou a rede como protagonista foi o físico austríaco Fritjof Capra [1], autor de A teia da vida, obra de1996 que compila as várias contribuições da física, da matemática e da biologia para a compreensão dos sistemas vivos e, especialmente, de seu padrão de organização. Capra [1] identifica a rede com esse padrão comum a todos os organismos vivos.

O cientista social espanhol Manuel Castells [2] também é uma das referências dos estudos de redes no campo das ciências sociais. Para Castells [2] as redes são uma estrutura social, um sistema aberto, altamente dinâmico e suscetível de inovação sem ameaças ao seu equilíbrio.

Outra característica singular de uma rede é a sua capacidade de operar de modo linear sem a necessidade de hierarquias. Do mesmo modo, na rede social de caráter estritamente institucional, há fenómenos organizativos não verticais e não hierárquicos, funcionando produtivamente.

A primeira pré-condição da rede é a participação voluntária: pessoas ou organizações participam da rede quando querem e porque assim o desejam. Elas não são obrigadas a fazê-lo; decidem compartilhar do projeto coletivo da rede porque acreditam e investem nele.

Nas redes, a distribuição do poder é policéfala, pois uma rede não pode ter um comando central. É possível, no entanto, para fins logísticos, um grupo representativo tomar, por períodos preestabelecidos, a organização da rede, sem, no entanto, criar um sistema de subordinação entre as múltiplas lideranças. Articulá- las implica, além de conectividade, comunicação, uma operação conjunta e um tipo especial de coordenação.

O propósito de existência de uma rede tem o mesmo papel do poder de mando nos sistemas verticais hierárquicos. Lipnack e Stamps [3], expressam-se assim quanto ao assunto: O propósito faz o papel de coordenador tradicionalmente desempenhado pelo comando e o controle centralizados. A força do propósito mantém a coesão entre os participantes (...), unifica elementos díspares, atuando como se fosse uma força centrífuga. O propósito substitui os adesivos tradicionais - por exemplo, a coesão hierárquica e as instruções escritas da burocracia (...). Diante de mudanças rápidas, os mecanismos tradicionais de controle causam tropeços. O propósito oferece contexto para a ação (p 45)

O surgimento de uma rede ocorre quando um propósito comum consegue aglutinar diferentes atores, formando-se o grupo [4] e convocá-los para a ação. O elemento de coesão das redes é uma ideia-força, uma tarefa, um objetivo. Algo que parece frágil como princípio organizacional, mas que quando potencializado pela ação voluntária se constitui em um poderoso agente de transformação. Segundo Passarelli [5], "redes são pessoas que anseiam por conversar, se apresentar, compartilhar conhecimentos tácitos, pensamentos críticos, conhecimentos científicos ou se unir para alcançar maior influência (p. 325).

No campo da cooperação internacional, tem-se a compreensão atual de que uma rede não se limita às organizações e fóruns internacionais convocados pelos Estados, mas igualmente por alianças e estratégias com e entre vários atores, como organizações da sociedade civil, da iniciativa privada, entidades académicas e outros [6].

Egger [7] dispõe que as redes podem ser informais/sociais ou redes formais. As primeiras são mapas de relacionamento pessoais, amizade ou negócios, consistindo de relações informais individuais. As últimas são "grupos ou pessoas correlacionados de várias instituições ou organizações independentes estabelecidas de acordo com um propósito ou necessidade específica" [7] (p. 13) são as chamadas redes sociotécnicas.

A rede sociotécnica pode ser vista como o coletivo híbrido [8] constituída pelo intercâmbio de capacidades humanas e institucionais em suas funções técnicas que compartilham boas práticas para saltos qualitativos de caráter duradouro para as partes envolvidas.

A rede sociotécnica é transdisciplinar, na medida em que a produção, reprodução e difusão de conhecimentos são heterogéneas, mas amplamente acessíveis aos seus integrantes. As suas ténues fronteiras fazem convergir uma multiplicidade de competências e experiências complexas [9]. Em sendo relacional, é também estruturalmente condicionada, na medida em que é constituída por indivíduos ou grupos socialmente posicionados. As interconexões entre indivíduos, os seus agrupamentos e comunicação merecem a devida ênfase, para se compreender a inserção social e a distribuição do poder [2].

A Rede Ibero-americana de Direito Sanitário (RDS) foi criada formalmente em 2011, a partir de um encontro de académicos na área do direito e da saúde pública, na Faculdade de Ciências Jurídicas da Universidade de Buenos Aires (UBA), Argentina, porém a sua conceção ocorreu dois anos antes, em reunião na cidade de Brasília, 
Brasil, com inúmeros membros de universidades e instituição de pesquisa, num evento denominado Taller Internacional de Derecho Sanitário.

Constituiu-se com a finalidade de ampliar os debates sobre o efetivo exercício do direito à saúde nas comunidades Ibero-americanas, por meio de articulação e cooperação técnica entre pessoas e instituições.

O direito é uma importante ferramenta para a saúde pública e as relações entre o médico e o paciente. Apesar de sua importância, a disciplina não é ensinada nas universidades e poucos pesquisadores têm como tema de seus estudos o direito à saúde, ou direito sanitário.

A RDS tem associados a título institucional como a título pessoal. Do primeiro tipo, existem como associados parte das universidades públicas e privadas da região Ibero-americana. Em nível pessoal, a rede conta com 103 associados, entre pesquisadores, professores universitários, alunos de graduação e pós-graduação, nas áreas do direito e da saúde pública.

A Rede Ibero-americana de Direito Sanitário apresenta uma morfologia típica de uma rede sociotécnica convencional em que não se observa um comando, mas conectividade cooperativa entre seus componentes, que ora se faz ou desfaz, a critério de interesses de pesquisa ou educacional dos parceiros. Tem sua composição em elementos académicos advindos dos países componentes das Regiões Ibérica na União Europeia, América do Sul, América Latina, América Central e América do Norte.

A organização da RDS tem base em três órgãos: Assembleia Geral, Conselho Diretor e Secretaria Executiva. Trata-se de uma rede nucleada, em que os membros estão diretamente vinculados a um núcleo formado por um conselho diretor eleito entre os pares, quando reunidos em Assembleia, por um período de 4 anos. À Secretaria Executiva compete apoiar administrativamente as ações do Conselho Diretor.

Os meios de comunicação com uso de ferramentas tecnológicas facilitam o diálogo interativo dos grupos. A RDS fez largo uso do Internet Realtime Conference (IRC), conhecido como chat, além de software que permitiu troca de mensagens eletrónicas (e-mails). A videoconferência também foi utilizada para interação sincrónica. Para as reuniões e oficinas permanentes, foram utilizadas técnicas de groupware [10,11].

Neste contexto, a Figura 1 representa como a rede se configura. A figura é a preparação para análise de rede detalhada ao longo do texto, e de como se comportou no período de 2011 a 2015.

Em 2012, a RDS com o intuito de difundir e estimular o desenvolvimento do Direito Sanitário na região Ibero-

Desenvolvimento de Ferramenta Online

Para o Direito à Saúde

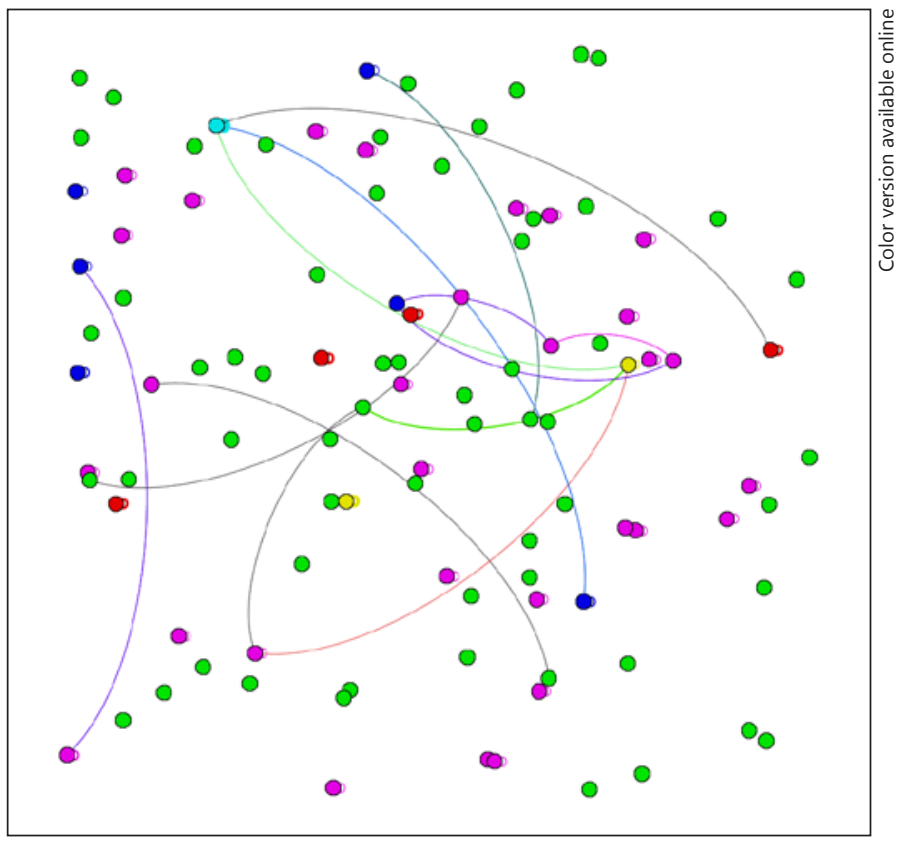

Fig. 1. Morfologia da Rede Ibero-americana de Direito Sanitário. Fonte: Dados obtidos nos documentos disponíveis no sítio da RDS (http://rededireitosanitario.fiocruz.br/?page_id=2\&lang=pt).

americana, divulgar a produção científica dos profissionais e instituições que a compõe e promover o debate dos grandes temas e dos principais desafios do direito à saúde contemporâneo, lançou publicação científica intitulada Cadernos Ibero-Americanos de Direito Sanitário (CIADS).

O CIADS se constitui em uma publicação eletrónica, de acesso livre e gratuito, disponibilizado trimestralmente na Internet no endereço http://www.cadernos. prodisa.fiocruz.br/index.php/cadernos. Aceita trabalhos redigidos em português, espanhol e inglês e opera com a modalidade de double blind peer review.

O financiamento da RDS se dá pelo aporte de recursos de seus membros, individuais ou institucionais. As instituições devem financiar o deslocamento de seus pesquisadores para a participação nos congressos e reuniões científicas e, também, apoiar financeiramente a realização dos Congressos da Rede, quando realizados no país em que o membro institucional está situado.

Os associados individuais por sua vez, podem capitanear recursos em seus países, nas diversas agências de fomento ou em órgãos de apoio, para a realização de projetos com outros membros da rede, de modo a promover a cooperação técnica e científica. 
A Organização Pan-Americana da Saúde, por sua representação no Brasil, no primeiro ano de existência da rede, foi a financiadora das atividades académicas e científicas. Este aporte inicial foi de fundamental importância para alavancar a estruturação da rede e dos primeiros trabalhos de pesquisa em colaboração.

Não há fontes privadas de provimento de fundos, mas apenas fontes públicas de financiamento, embora a rede conte com instituições privadas de ensino como membros.

Este artigo é o resultado de estudo de caso e examina os métodos, obstáculos e limitações encontradas no desenho e desenvolvimento da Rede Ibero-Americana de Direito Sanitário.

\section{Metodologia}

Tratou-se de um estudo de caso12 com abordagem quali-quanti e unidade de análise a organização constituída por instituições académicas e pesquisadores, com existência no ciberespaço denominada "Rede Ibero-americana de Direito Sanitário" (RDS). O estudo de caso como modalidade de pesquisa do como um fenómeno de certa natureza ocorrendo num dado contexto [12]. A utilização de um único caso revelador é apropriada, pois inexistem situações semelhantes para que sejam feitos estudos comparativos.

Segundo Yin [12], o estudo de caso representa uma investigação empírica com método abrangente desde o planejamento até a análise de dados. Pode incluir um caso único com abordagens quantitativas e qualitativas. Os casos mais comuns dessa espécie de investigação são os que têm foco numa unidade, quer seja o indivíduo quer uma organização.

A pesquisa teve caráter instrumental, descritivo-analítico e retrospectivo. O estilo de relato é informal e narrativo.

Os documentos analisados foram disponibilizados pela secretaria executiva da RDS, cuja existência esteve fisicamente localizada na Fundação Oswaldo Cruz, Fiocruz, instituição de ensino e pesquisa em saúde pública, na sua Unidade de Brasília, Brasil, até agosto de 2015. Os documentos foram: regimento da rede e suas subsequentes emendas, atas e pautas de reuniões ocorridas no quinquénio investigado, relatórios de gestão e planos de trabalho.

As publicações em coautoria foram utilizadas como parâmetro para justificar a cooperação entre os membros, utilizando-se como fonte de dados os livros e capítulos de livros, artigos publicados no periódico científico denominado Cadernos Ibero-americanos de Direito Sanitário (ISSN 2358-1824) e trabalhos científicos apresentados nos cinco congressos internacionais promovidos pela RDS. Identificada a autoria desses trabalhos, os nomes dos autores e co -autores foram inseridos em planilha no mesmo número de vezes em que foram identificados trabalhos publicados nas fontes pesquisadas, formando assim o banco de dados utilizado na pesquisa. A planilha foi transportada para o software de análise de redes, fazendo surgir as conexões entre autores e evidenciando aqueles que mais produziram cientificamente. Ressalte-se que a análise levou em conta apenas a colaboração em coautoria, desprezando-se as citações entre os membros da rede em suas publicações.
Não foram computados na pesquisa os acordos, convénios e termos de cooperação firmados entre instituições e universidades membros da RDS, embora existam.

Utilizou-se a metodologia de análise das redes sociais que se concentra na relação entre as unidades sociais que interagem na forma de padrões ou regularidades de relacionamento [13]. A análise possibilitou avaliar os aspectos descritivos dos relacionamentos e as análises estatísticas causais de tais fenómenos [13-16].

No aspecto qualitativo, a análise utilizou a proposta baseada nas medidas de centralidade (de grau e de intermediação), de coesão social (propriedades de mutualidade dos laços e de proximidade e alcance) e de densidade (laços) [16].

Para a construção das imagens utilizaram-se os softwares Gephi, software livre, gratuito e multilíngue (https://gephi.github. io/), na sua versão 8.2 .

Para a construção da nuvem de palavras utilizou-se o software IRAMUTEQ (versão 0.7 Alpha 2, disponível em: https:// http:// www.iramuteq.org/) e como fonte, os artigos e capítulos produzidos no âmbito da rede no período investigado.

\section{Resultados e Discussão}

A Rede Ibero-americana de Direito Sanitário é composta de 17 membros a título institucional e 103 membros a título individual, sendo 50 do sexo feminino e 53 do sexo masculino. Os membros são, em sua maioria, pesquisadores e professores vinculados a universidades e centros de pesquisa e formação relacionada ao direito e à saúde pública.

A RDS nasceu e funciona com objetivos bem delimitados: (1) a necessidade de discussão da legislação sanitária em nível regional; (2) o estabelecimento de parâmetros comparativos do arcabouço legislativo da saúde nos diversos países constitutivos da Região Ibero-América; (3) a definição da metodologia comum para as investigações e pesquisas no tema do Direito à Saúde e, (4) a reunião da produção científica e intelectual dos diversos núcleos participantes, publicitando-os.

Os membros que compõem a RDS estão distribuídos em três continentes, sendo uma maior concentração no continente sul americano (65), seguidos do europeu (19) e norte americano (19). A representação de género faz-se equilibrada, com leve aumento na proporção masculina.

A RDS tem participação de países periféricos e países centrais. Dos países participantes no hemisfério sul, apenas as Guianas, Suriname, Bolívia e Paraguai ainda não têm representatividade na RDS, todos os demais participam como instituições universitárias e/ou pesquisadores.

A Figura 2 demonstra que o país com maior quantidade de pesquisadores é a Argentina com 23,34\%, seguido pelo Brasil com 20,00\% e Espanha com 12,5\%. A maior inserção de membros na RDS da Argentina explica-se por 


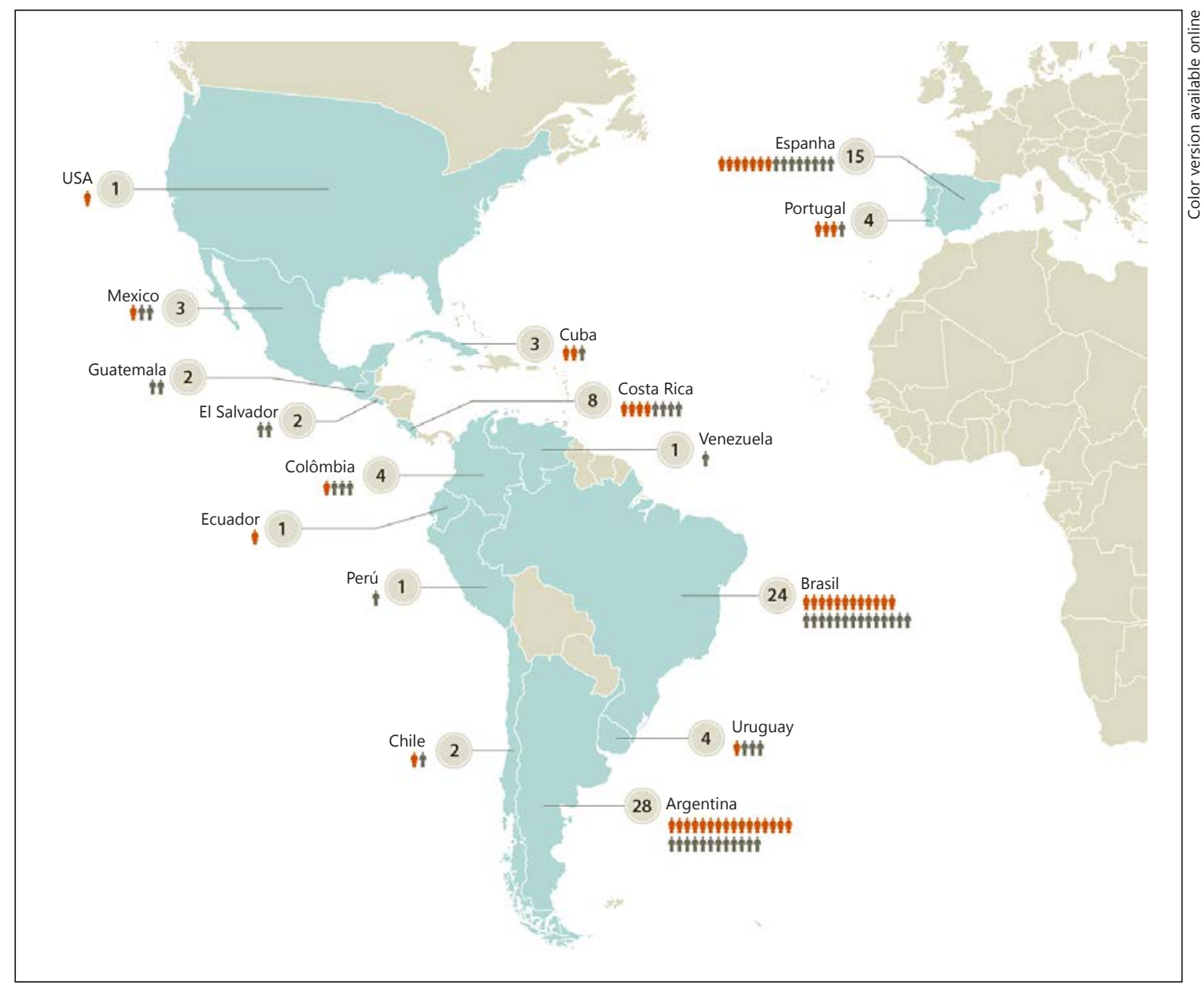

Fig. 2. Distribuição dos membros na RDS nos diferentes continentes 2011-2015. Fonte: Informações coletadas nos documentos da Rede Ibero-americana de Direito Sanitário.

ser o local em que se deu a criação da rede, seguida do Brasil, sede de sua secretaria executiva, até 2015. A Figura 3 apresenta a análise da produção científica dos membros da RDS (artigos, periódicos, livros e anais). O total da produção científica e intelectual encontrado somam 57 produções de diversos tipos realizadas por 34 autores, no período de 2011 a 2015.

A coautoria é frequente na produção intelectual na RDS. Não foram encontradas produções isoladas. Há um destaque para Delduque, seguido de Aizenberg, Badim e Cayón.

Tratam-se de pesquisadores de referência para os demais com expressiva influência na própria rede. Juntos e com os demais integrantes a eles interligados, formam o que é conhecido como "componente gigante": grupo formado por um número considerável de conexões, destacando-se dentro da própria Rede. A topologia, a qualida- de e a intensidade destas ligações são os principais fatores de acoplamento entre cada ator e a rede como um todo, na consecução dos objetivos individuais e do grupo, e no exercício de poder [14]. A posição de centralidade é associada ao poder de comunicação e cooperação, estar no centro da rede significa ter menos restrições e mais oportunidades de relações que se estabelecem entre os atores. Definir uma posição mais ou menos favorável não é uma tarefa simples e definitiva, mas as análises de redes sociais têm contribuído bastante para uma melhor compreensão do poder que pode ser atribuído a determinados atores dentro das estruturas de relações sociais [13].

Delduque tem 11 ligações com Badim; Dallari e Aith tem 9 ligações por coautoria; e Aizenberg e Rotman apresentam 7 ligações. São atores com a proximidade de conhecimento na inteligência cooperativa para a saúde. 
Fig. 3. Atores conectados por coautoria na Rede Ibero-Americana de Direito Sanitário. Fonte: Periódicos, artigos e livros indicados para a pesquisa; produzido pelo software Gephi.

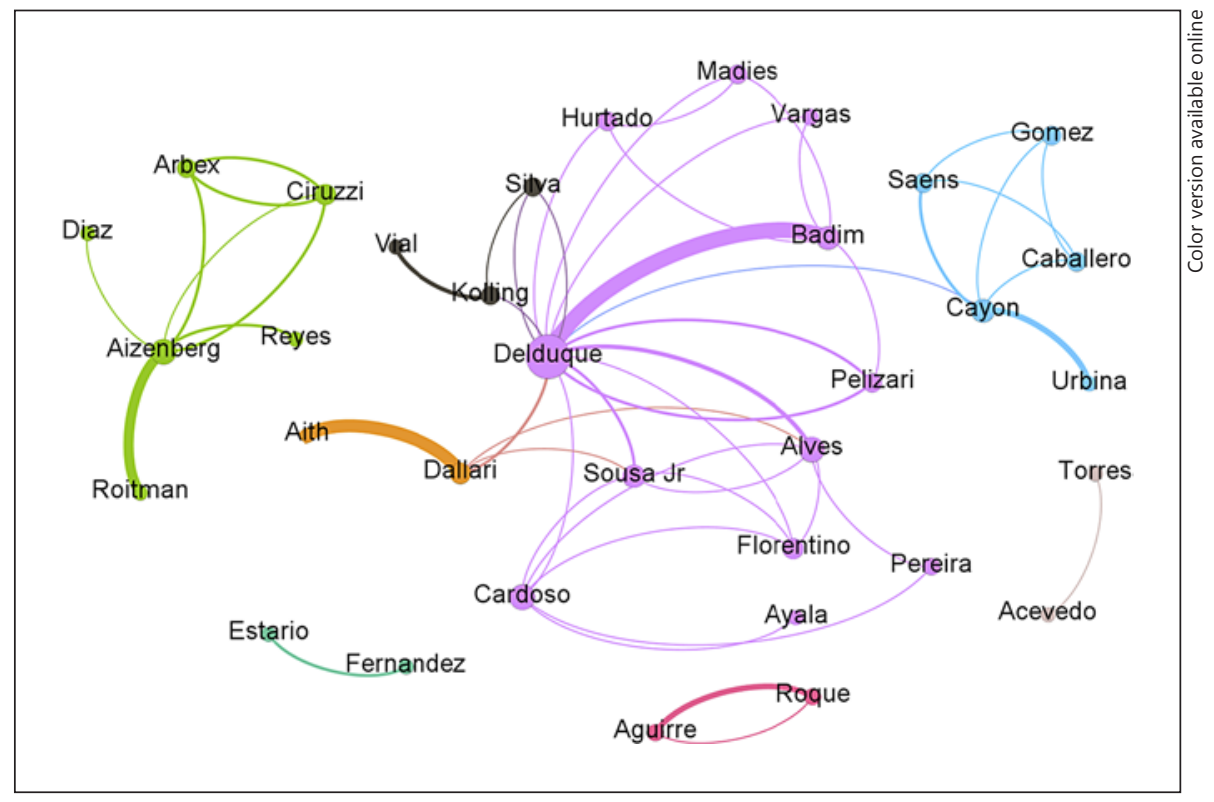

Há também subgrupos de conexão entre pesquisadores sem, necessariamente, vinculação com o centro. Tais subgrupos representam pesquisadores de nacionalidade idêntica e pertencentes a uma mesma instituição.

Há a presença de díades (par de atores e a relação entre eles). As 3 duplas (demarcados com setas) trabalharam na periferia da rede sem conexões com ela. Também Vanni et al. [17] encontraram resultados semelhantes em análise de rede em HIV.

As marcações da figura demonstram os subgrupos da rede por sua dimensão, sendo que o maior é composto por Delduque, Badim, Alves, Sousa Jr, Cardoso e outros. A conexão entre Delduque e Cayón forma o segundo maior grupo da rede. Mas Cayón mantém, paralelamente, parceria com subgrupo de trabalho com quatro outros pesquisadores, na periferia da rede.

A Análise de Redes Sociais não diz respeito apenas à coleção de díades, tríades e subgrupos, mas à habilidade de modelar as relações entre sistemas de atores. Os laços sociais são uma medida de capital social, um ativo a ser usado pelo ator, caminhos de fluxo da informação e de poder: "uma pessoa que está ligada a pessoas que não estão diretamente ligadas entre si, tem oportunidade de mediar entre elas e de tirar proveito desta mediação" [18].

A Figura 4 é a representação da produção académica dos membros da RDS no seu veículo de comunicação científica, os Cadernos Ibero-Americanos de Direito Sanitário (CIADS), no período de 2012 a 2015. Dos 103 membros da rede a título individual, foram encontradas 51 ligações de coautoria.

Visualmente a Figura 4 apresenta pesquisadores separados e com poucas ligações. O periódico criado para a divulgação dos trabalhos e pesquisas realizados pela rede não tem sido explorado nesse sentido. Ficou demonstrado que outros veículos são preferíveis para a difusão de resultados de pesquisas pelo grupo da rede.

No que se refere ao periódico, a produção se destaca especialmente por Delduque e Carignani que fazem colaboração com Romero, Alves, Ortega e Robledo. Os autores destacados têm maior possibilidade de intermediação na comunicação cientifica. Quanto mais atores dependerem desses pesquisadores para realizar conexões, mais poder têm para negociar contatos, estimular conexões e firmar parcerias. Os pesquisadores mais produtivos tendem a ser mais colaborativos [19].

Destaca-se visualmente uma tríade de colaboração entre Rovira, Decia, La Rosa, e quatro duplas de cooperação: Zalazar e Puccio; Merino e Ruiz; Arias e Luna; e Aizenberg e Ciruzzi.

As conexões ocorridas entre os pesquisadores da RDS no âmbito da revista são mais frequentes quando comparadas com as conexões percebidas nos outros veículos estudados.

$\mathrm{Na}$ Figura 4, a região 1 apresenta atores com publicações individuais, nos CIADS. Representam 58,25\% do total de membros da rede aqueles sem publicação na revista, apesar de ter sido criada para difundir os estudos e 


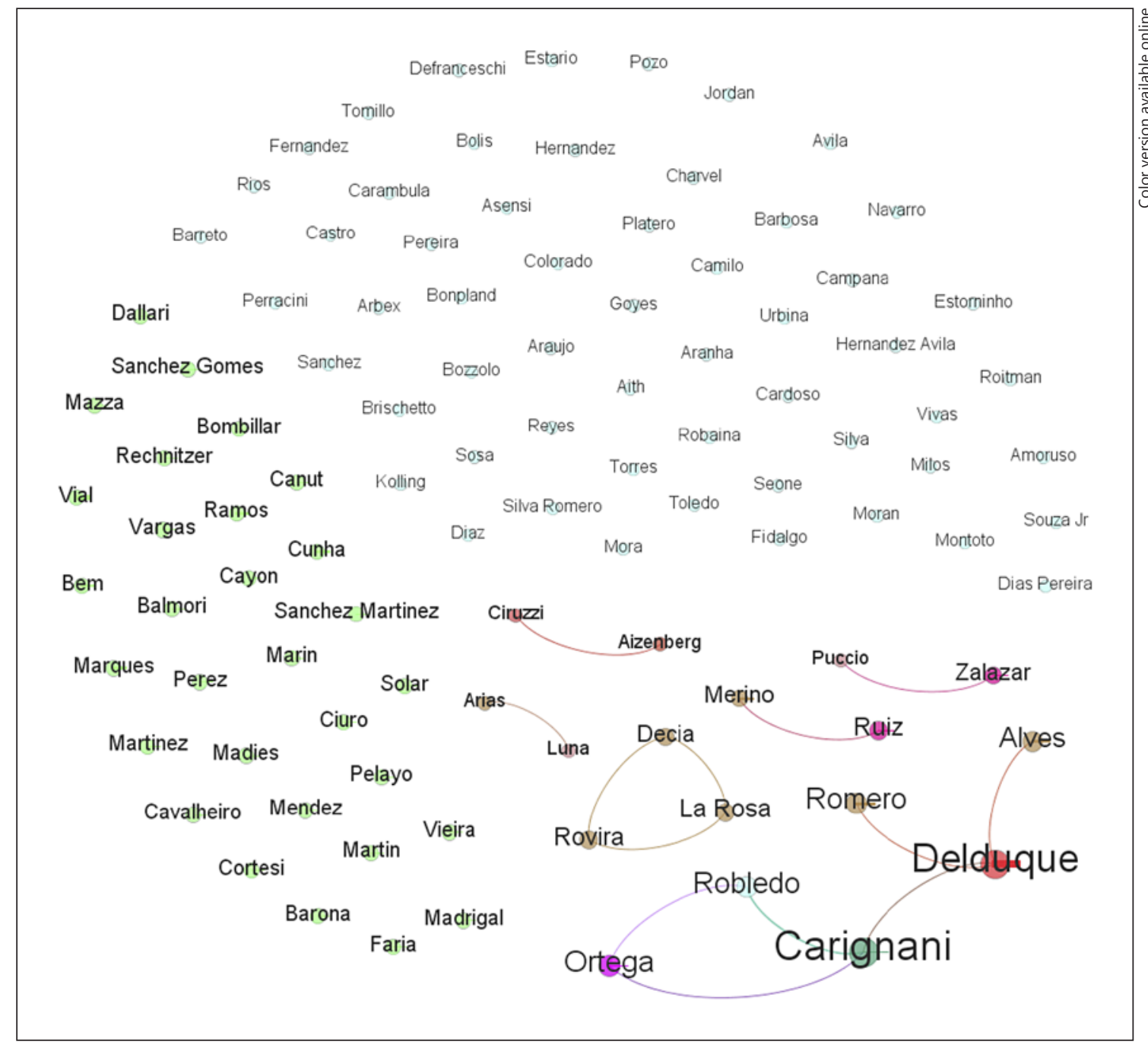

Fig. 4. Rede de coautoria no periódico científico CIADS entre 2012-2015. Fonte: Cadernos Ibero-Americanos de Direito Sanitário (http://www.cadernos.prodisa.fiocruz.br/index.php/cadernos).

pesquisas desses membros (região 2). O restante dos $40.78 \%$ apresentaram entre 1 e 4 trabalhos no período de publicação do periódico e apenas $0.97 \%$ publicaram 9 trabalhos.

Essa disparidade de dados demonstra que poucos atores apresentam um papel central na comunicação e cooperação da RDS, estando o poder da Rede Ibero-Americana de Direito Sanitário concentrado em poucos pesquisadores capazes de produzir relações de trabalho e colaboração.

A Figura 5 demonstra os temas mais frequentes ocorridos na produção científica total da rede.

Desenvolvimento de Ferramenta Online Para o Direito à Saúde
O direito à saúde se sobrepõe aos demais temas estudados pelos membros da rede, acompanhado do tema direito sanitário. Mas medicamentos, judicialização e produção legislativa em saúde também foram temas escolhidos pelos pesquisadores. A questão da regulação na área da saúde pública aparece como temática de estudos e publicações no âmbito da rede, tema em que o direito tem muito a colaborar com a saúde pública. A palavra responsabilidade também aparece com destaque na nuvem de palavras. Na relação médico e paciente o tema da responsabilidade é tratado muito frequentemente e as ciências jurídicas têm muito a contribuir para essa temática. 


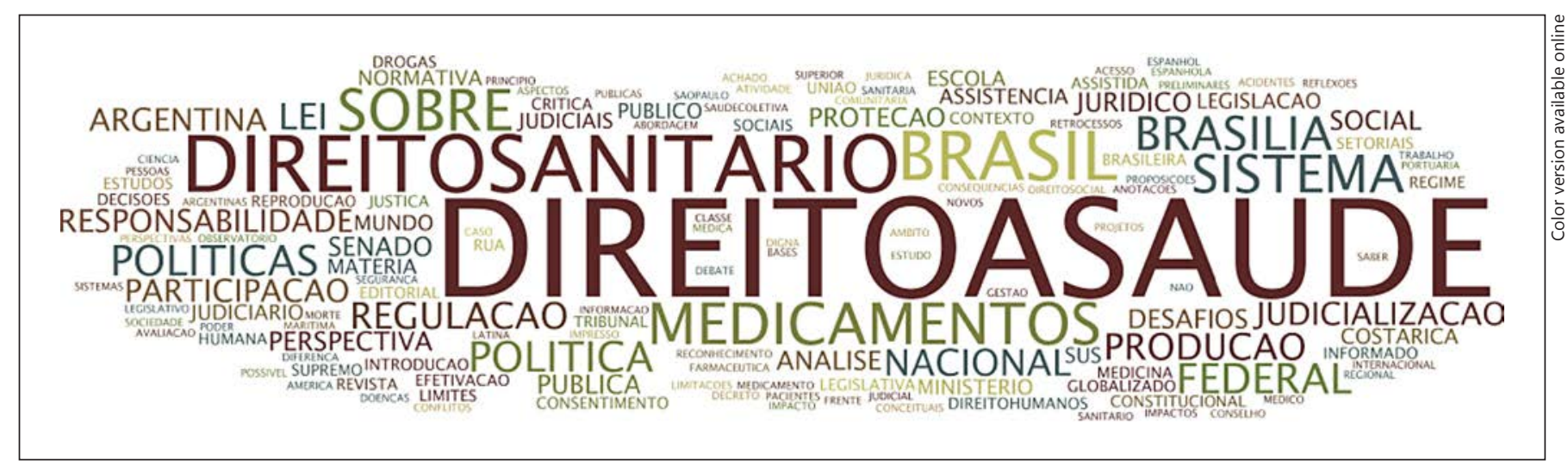

Fig. 5. Temas mais recorrentes na produção científica total dos membros da RDS. Fonte: Artigos, capítulos, livros e anais de congressos produzidos por membros da RDS.

\section{Conclusões}

As grandes distâncias que separam os poucos pesquisadores do tema direito à saúde em escala global dificultam a troca de conhecimento e cooperação científica. Em vista disso, foi constituída uma rede sociotécnica de conhecimento científico com o propósito de servir como veículo de comunicação entre os membros sobre direito à saúde e aproximá-los.

O modo de implementação da rede, sem um centro, mas dotada de um grupo central responsável pelas ações diretivas e uma secretaria executiva com competência para a administração da rede fez com que houvesse uma centralidade na produção de pesquisa e estudos em colaboração. Isso porque os integrantes dessas instâncias tiveram mais contato entre si favorecendo a cooperação. Isso fez com que um largo número de integrantes não tivesse a oportunidade de participar, ficando à margem da rede.

Por outro lado, as realizações ocorridas em apenas 5 anos demonstraram o amadurecimento do grupo de estudiosos, que apesar de estarem em países diferentes e falando idiomas distintos souberam, por meio da tecnologia de comunicação, difundir seus conhecimentos e realizar atividades de produção intelectual.

As tecnologias que permitem a construção de espaços como o da RDS são essenciais para a difusão de conhecimentos como o do Direito à Saúde. O direito sanitário que não recebe incentivos da maioria das universidades e instituições de pesquisa em saúde pública tem nessa forma de agregar pesquisadores sua melhor oportunidade para realizar pesquisas jurídicas sobre as questões de saú-

de e construir os marcos teóricos e metodológicos da nova disciplina.

O grau de intermediação na rede é prejudicado por ainda manter grupos e pesquisadores na sua periferia, sem ações que possam incorporar tais elementos à produtividade geral da RDS. No que se refere à coesão social, a mutualidade dos laços quando existentes favorecem a cooperação internacional de pesquisadores e a produção de conhecimento. A Rede Ibero-americana de Direito Sanitário mantém um centro denso e a periferia difusa, o que não favorece sua consolidação e desenvolvimento, porém a situação poderá ser superada com a maturidade do grupo e subgrupos a partir da eleição de novos membros para o conselho diretivo e secretaria executiva.

References

Port J Public Health 2017;35:1-9 DOI: $10.1159 / 000477644$
1 Capra F: A teia da vida. São Paulo, Editora Cultrix, 2012.

2 Castell M, Cardoso G: org. Sociedade em rede: do conhecimento à acção política: Conferência promovida pelo Presidente da República, 4 e 5 de Março de 2005, Centro Cultural de Belém. Lisboa, Imprensa Nacional-Casa da Moeda, 2005. Acesso em 23 jun. 2015. Disponível em http://www.cies.iscte.pt/destaques/documents/ Sociedade_em_Rede_ CC.pdf.

3 Lipnack J, Stamps J: Rede de informações. São Paulo, Editora Makron, 1994.

4 MacGrath JE: Groups: Interaction and Performance. New Jersey, Prentice Hall, 1984.

5 Passarelli B: Aprendizagem on-line por meio de comunidades virtuais de aprendizagem; in Litto FM, Formiga MMM (org): Educação a distância: o estado da arte. São Paulo, Pearson Education do Brasil, 2009, pp 325-331. 
6 Campos RF: A Rede Ibero-americana de Direito Sanitário: uma proposta para se avançar na garantia do Direito à Saúde. Rev Tempus Actas Saúde Col 2013;7:91-106.

7 Egger UK, Glueck M, Buchholz G, Rana G, Arhidani S: Work the net: um guia de gerenciamento para redes formais. Rio de Janeiro, GTZ, 2007. Acesso em 23 jun. 2015. Disponível em http://www.giz.de/akademie/de/ downloads/gtz2008-0318pt-guia-redes-formais.pdf.

8 Aibar E: Las culturas de internet: la configuración sóciotécnica de la red de redes. Rev Cienc Tecnol Soc 2008;11:9-21.

9 Silva EL: Rede científica e a construção do conhecimento, 2002. Inf Soc: Estudos 2002; $12: 120-148$.
10 Coleman D, Khanna R: An overview of groupware; in Coleman D, Khanna R (eds): Groupware Technology and Applications. New Jersey, Prentice Hall, 1995, pp 3-41.

11 Alter S: Information Systems: A Management Perspective, ed 2. New York, Addison-Wesley, 1996.

12 Yin RK: Estudo de caso: planejamento e métodos. Porto Alegre, Bookman, 2015.

13 Hanneman RA: Introduccion a los métodos del analisis de redes sociales. Riverside, Universidad de California Riverside, 1998.

14 Hanneman RA, Riddle M: Introduction to Social Network Methods. Riverside, University of California, 2005. Acesso em 10 mar. 2014. Disponível em http:// faculty.ucr.edu/ hanneman
15 Scott J: Social Network Analysis: A Handbook, ed 2. London, Sage Publications, 2002.

16 Wasserman S, Faust K: Social Network Analysis: Methods and Applications. Cambridge, Cambridge University Press, 1994.

17 Vanni T, Mesa-Frias M, Sanchez-Garcia R, Roesler R, Schwartsmann G, Goldani MZ, et al: International scientific collaboration in HIV and HPV: a network analysis. PLoS One 2014;9:e93376.

18 Nooy W, Mrvar A, Batagelj V: Exploratory Social Network Analysis with Pajek. New York, Cambridge University Press, 2005.

19 Meadows AJ: A comunicação científica. Brasília, Briquet de Lemos, 1999. 